Acta horticulturae et regiotecturae 2

Nitra, Slovaca Universitas Agriculturae Nitriae, 2014, p. 38-42

\title{
POLLUTION SPREAD ANALYSIS IN THE MALÁ NITRA RIVER BY USING OF 1-D MODEL
}

\author{
Yvetta VELÍSKOVÁ*1, Peter HALAJ², Marek SOKÁČㄹ, Viliam BÁREK ${ }^{2}$ \\ 'Institute of Hydrology, Slovak Academy of Sciences, Bratislava, Slovak Republic \\ ${ }^{2}$ Slovak University of Agriculture in Nitra, Slovak Republic
}

\begin{abstract}
The Water Framework Directive (WFD) is a key initiative aimed at improving water quality throughout the EU. The development of the computer technologies enables us to solve the ecological problems in water management practice very efficiently. The mathematical and numerical modelling allows evaluating various situations of contaminants spread in rivers (from everyday wastewater disposal through the fatal discharges of toxic substances) without immediate destructive impact on the environment. The paper deals with 1-dimensional numerical model HEC-RAS and its response on various values of dispersion coefficient. This parameter is one of the most important input data for simulation of pollution spread in streams. There were performed tracer experiments in the Malá Nitra River and results of these measurements are compared with results of numerical simulations. The values of the longitudinal dispersion coefficient were estimated from this comparison. The range of mean values of this coefficient determined on the base of numerical model application was $0.05-0.13 \mathrm{~m}^{2} \mathrm{~s}^{-1}$, for the other flow condition it was $0.07-2.5 \mathrm{~m}^{2} \mathrm{~s}^{-1}$ or $0.28-0.6 \mathrm{~m}^{2} \mathrm{~s}^{-1}$. The next task was carrying out the model sensitivity analysis, which means to evaluate input data influences, especially longitudinal dispersion coefficient, on outputs computed by 1-dimensional simulation model HEC-RAS. According to the results it can be said that the model HEC-RAS responds to longitudinal dispersion coefficient value changes adequately, suitably and proportionately. The application of the model HEC-RAS demonstrated the eligibility for simulation of pollution spread in streams, which means that it is a suitable tool allowing a reasonable support in decision making process connected to river water quality management.
\end{abstract}

Keywords: surface flow, spread of pollution, longitudinal dispersion coefficient, HEC-RAS model, sensitivity analysis

In order to prevent harmful effects of pollution on aquatic environment and also human health, the EC Water Framework Directive (WFD, 2000/60/EC) came into force in 2000 as a part of the EU environmental legislation. The implementation of the WFD has been a challenge for all of the EU member countries.

The development of the computer technologies enables us to solve the ecological problems in water management practice very efficiently. The mathematical and numerical modelling allows evaluating various situations of contaminants spread in rivers (from everyday wastewater disposal up to the fatal discharges of the toxic substances) without immediate destructive impact to the environment. There has been developed a lot of mathematical and numerical models to simulate water quality. These models are able to simulate the real situation at streams, however the range of the reliability and accuracy of the results is very wide (Abbott, 1978; Jolánkai, 1992; Pekárová, Velísková, 1998; Říha, et al., 2000; Rankinen, et al., 2002; Mclnstyre, 2005).

When a conservative pollutant is released into a river, physical processes such as advective transport and dispersion determine the movement and change in concentration of the pollutant. The transport process of the pollutant can be conveniently viewed as being composed of three stages. In the first stage, the pollutant is diluted by the flow in a channel because of its initial momentum. In the second stage, the pollutant is mixed throughout the cross-section of a river by turbulent transport processes.
In the third stage, after the cross-sectional and the vertical mixing is complete, longitudinal dispersion tends to erase any longitudinal variation in the pollutant concentration (French, 1986). Thus, from this moment on it is possible to simulate pollution transport one-dimensionally.

This study deals with evaluation and quantification of input data influences on outputs of dispersion simulation models, especially with longitudinal dispersion coefficient impact as one of the main parameters of dispersion process in 1-D simulations. This publication is the result of the project APVV-0274-10, which is concentrated on the evaluation of abilities, limitations, strengths and weaknesses of the current level of how to solve the qualitative problems of surface flows, with a focus mainly on approach for hydrodynamic dispersion in surface water. It is also the result of the project ITMS 26240120004 Centre of excellence for integrated flood protection of land implementation, supported by the Research \& Development Operational Programme funded by the ERDF.

\section{Material and methods}

The transport of pollution in surface and subsurface waters is generally described with the advectiondispersion equation (ADE). The ADE distinguishes two transport modes: advective transport as a result of passive movement along with water, and dispersive/diffusive transport to account for diffusion and small-scale variations 
in the flow velocity as well as any other processes that contribute to solute spreading. ADE comes from the mass balance equation (van Genuchten, et.al, 2013), which can be formulated in a general manner by considering the accumulation or depletion of solute in a control volume over time as a result of the divergence of the flux (i.e., net inflow or outflow), possible reactions, and the injection or extraction of solute along with the fluid phase. A variety of solute source or sink terms may need to be implemented in the ADE. Many other processes such as biodegradation or inactivation, radioactive decay, and production may affect the contaminant concentration. For relatively simple transport scenarios, the ADE can be represented in the one-dimensional form:

$$
\frac{\partial C}{\partial t}=D_{x} \frac{\partial^{2} C}{\partial x^{2}}-u \frac{\partial C}{\partial x}-\mu C+\vartheta
$$

where:

$u$ - the flow velocity $\left(\mathrm{m} \mathrm{s}^{-1}\right)$

$C$ - the pollution concentration expressed as mass per unit volume of water $\left(\mathrm{kg} \mathrm{m}^{-3}\right)$

$D_{x}$ - the longitudinal dispersion coefficient accounting for the combined effects of ionic or molecular diffusion and hydrodynamic dispersion $\left(\mathrm{m}^{2} \mathrm{~s}^{-1}\right)$

$x$ - the longitudinal distance/coordinate $(m)$

$\mu$ - a general first-order decay rate $\left(\mathrm{s}^{-1}\right)$

$\vartheta$ - a zero-order production term $\left(\mathrm{kg} \mathrm{m}^{-3} \mathrm{~s}^{-1}\right)$

Longitudinal dispersion is difficult to determine as it depends upon too many variables and their nonlinear inter-relationships. A large disparity exists between the values of dispersion coefficients obtained for idealized and simplified systems (such as irrigation channals) and for rivers (Rutherford, 1994). Such a disparity suggests that the processes contributing to dispersion in rivers are not well understood.

The knowledge of accurate value of longitudinal dispersion coefficient $D x$ is important for determining selfpurifying characteristics of streams, devising water diversion strategies, designing treatment plants, intakes and outfalls, and studying environmental impact due to injection of polluting effluents into the stream (David et al. 2002).

The investigated part of the water body was approximately 1,340 m long rearch of - the Malá Nitra River situated at the southwest part of Slovakia. The Malá Nitra River is a small, modified stream with basin area $A=76.6 \mathrm{~km}^{2}$. Discharge is regulated by operation with the weir located $15 \mathrm{~km}$ upstream in bifurcation point with The Malá Nitra River. Mean annual discharge is $0.550 \mathrm{~m}^{3} \mathrm{~s}^{-1}$. Cross sections had originally double-trapezoidal shape with bed width $b=4 \mathrm{~m}$, height $2.5 \mathrm{~m}$ and bank slope $1: 2$ with concrete revetments. However, the channel geometry along the stream has been slightly changed by natural morphological processes during the years. There exists relatively long straight part with small water depths (max. $0.65 \mathrm{~m}$ ). Longitudinal bed slope is $1.5 \%$. Measured discharge value during field experiments were $0.46 \mathrm{~m}^{3} \mathrm{~s}^{-1}$. On base of field measurements of water level between balanced cross sections the roughness coefficient $(n=0.035)$ was determined by energy grade line slope calculation.

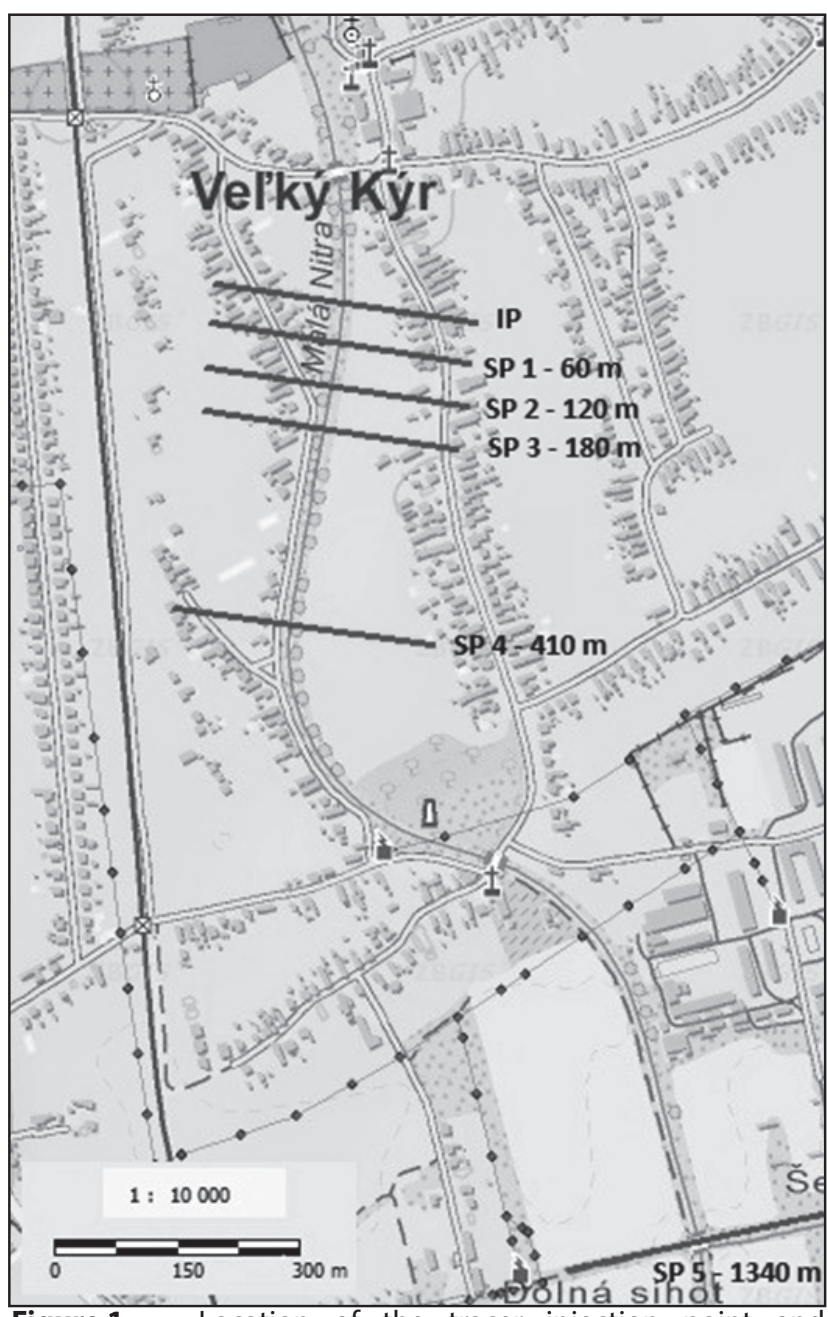

Figure 1 Location of the tracer injection point and sampling points on the Malá Nitra River

Tracer experiments, during which the tracer spreading in the current stream hydraulic conditions was monitored, were done in Vel'ký Kýr settlement region ( $\mathrm{N}+48^{\circ} 10^{\prime} 50^{\prime \prime}$, $\left.\mathrm{E}+18^{\circ} 09^{\prime} 19^{\prime \prime}\right)$. The solution of common salt $(\mathrm{NaCl})$ was used as a tracer. A single dose of tracer was $2 \mathrm{~kg} \mathrm{NaCl}$ in 50-60 I of water, representing approximately $11 \%$ of the actual discharge in the stream. The time course of tracer concentration, channel morphology and basic hydraulic parameters of water flow were monitored in several crosssections downstream from injection point and lasted until the background concentration value was reached. Velocity distribution and actual discharge were determined on base of measurements with Acoustic Doppler Velocimeter, Sampling points were at 60, 120, 180, 410 and 1,340 $\mathrm{m}$ from injection point (Figure 1). Concentration measurements were carried out in 6 stations of the monitored cross section. As a representative concentration profile course in time was chosen the cross section station with the most significant concentration increasing. On base of field measurement results, there were determined the values of longitudinal dispersion coefficient. The next aim was the evaluation of input data influences, especially longitudinal dispersion coefficient, on outputs of 1-D simulation model HEC-RAS ver. 4.1 (USACE, 2010), which can simulate the dispersion in streams. 
This model was developed by the United States Army Corps of Engineers and it is designed to model complex phenomena and processes occurring in surface waters of the river systems. This software allows the calculation of one-dimensional steady nonuniform and unsteady flow, solving of hydraulic engineering tasks, design of modifications stream channels, design of water works, pollution transport modelling, modelling of temperature of surface water, bed load transport, modelling of accumulation-erosion processes in stream channels, etc. An advection-dispersion module is included with the used version of HEC-RAS. This new module uses the QUICKEST-ULTIMATE explicit numerical scheme to solve the one-dimensional ADE using a control volume approach.

\section{Results and discussion}

As mentioned above, the longitudinal dispersion coefficient is one of the most important input data for the simulation of the model of dispersion in a stream. On the other hand, determination of this parameter is very difficult as it depends upon too many variables and their nonlinear inter-relationships. Various approaches to determine this value exist: from the own experience or that from the references, over the qualified estimates, up the special calculations application. Empirical relations have often limited validity: values given by them are applicable only in specific conditions and in some cases it is not possible to use any of them. Therefore,

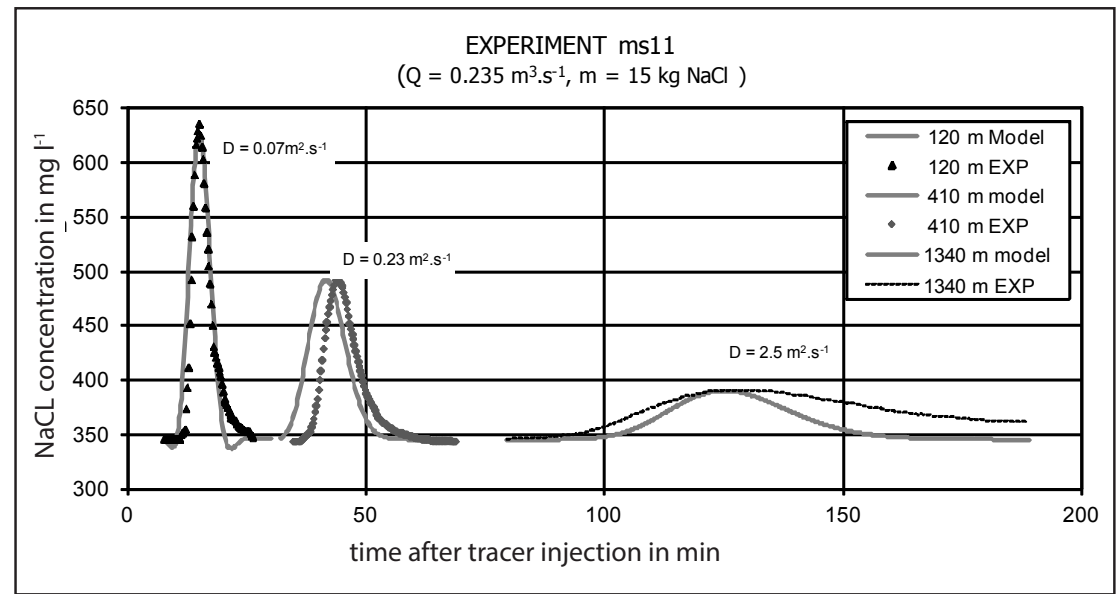

Figure 3 Concentration distribution during the experiment time - comparison of experiment results and results of the numerical model HEC-RAS in sampling cross-section profile at distance $120 \mathrm{~m}, 410 \mathrm{~m}$ and 1,340 m from injection point

it is necessary to give attention to conditions in which the relations were obtained and if those conditions were approximately consistent with conditions in which the relations will be applied. Next way how to find out the value of $D_{x}$ is an application of one-dimensional simulation model. In this case, the fluctuations of $D_{x}$ values are more significant. It can be supposed that the model simulates the flow conditions in more details, so the obtained values would be more accurate.

Firstly, we use monitored and measured data for determination of longitudinal dispersion coefficient. We have simulated tracer experiments with various values of longitudinal dispersion coefficient by the model HEC-RAS. The results of simulations were compared with the measured data obtained during the field determines thevalue of the longitudinal dispersion coefficient for each of the experiments. Figure 2 presents a comparison of concentration profiles obtained with the HEC-RAS model and the results measured during the tracer experiment in sampling points at distance $60 \mathrm{~m}, 120 \mathrm{~m}$ and $180 \mathrm{~m}$ from injection point, considering 10 $\mathrm{kg}$ of $\mathrm{NaCl}$ injected in the river channel for discharge $0.230 \mathrm{~m}^{3} \mathrm{~s}^{-1}$, average flow velocity of $0.17 \mathrm{~m} \mathrm{~s}^{-1}$ and computational cell size $2 \mathrm{~m}$.

The range of mean values of this coefficient determined on the base of numerical model application was $0.05-$ $0.13 \mathrm{~m}^{2} \mathrm{~s}^{-1}$, for the other flow condition it was $0.07-2.5 \mathrm{~m}^{2} \mathrm{~s}^{-1}$ or $0.28-0.6 \mathrm{~m}^{2}$ $\mathrm{s}^{-1}$. It is convenient to mention that these ranges of values are closer to values obtained in laboratory flume than in natural conditions (Fischer, measurements Minimum difference

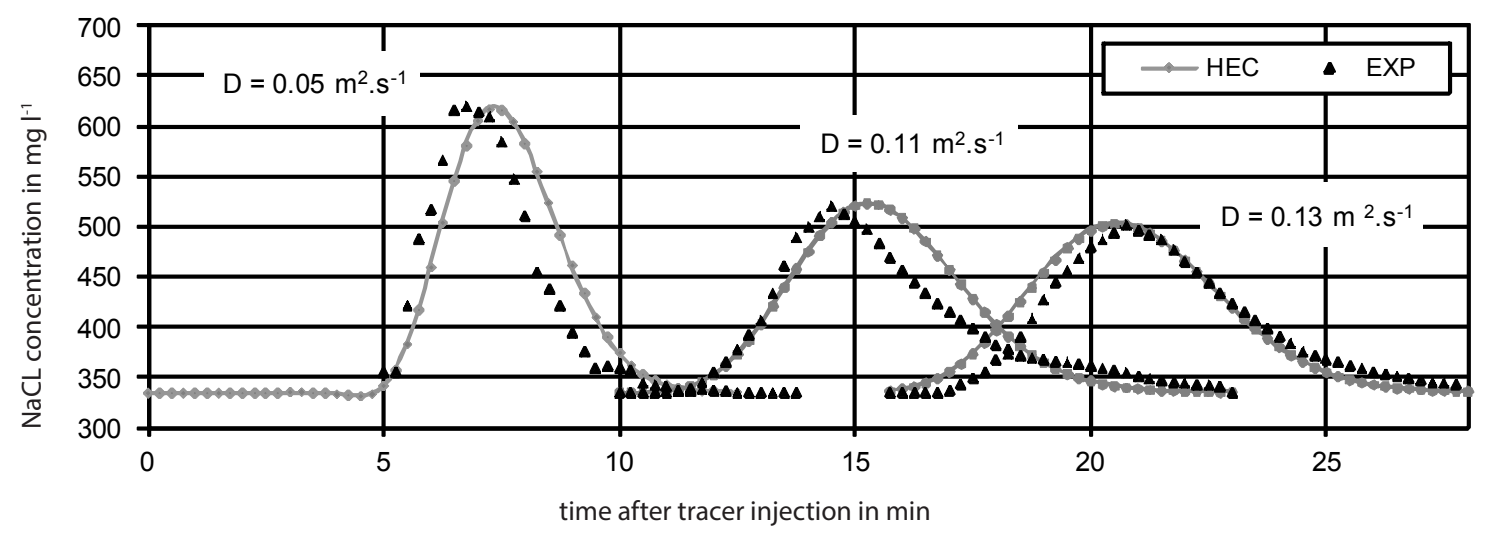

Figure 2 Comparison of concentration profiles obtained with the HEC-RAS model and the results measured during tracer experiment in the sampling points at distance $60 \mathrm{~m}, 120 \mathrm{~m}$ and $180 \mathrm{~m}$ from the injection point 


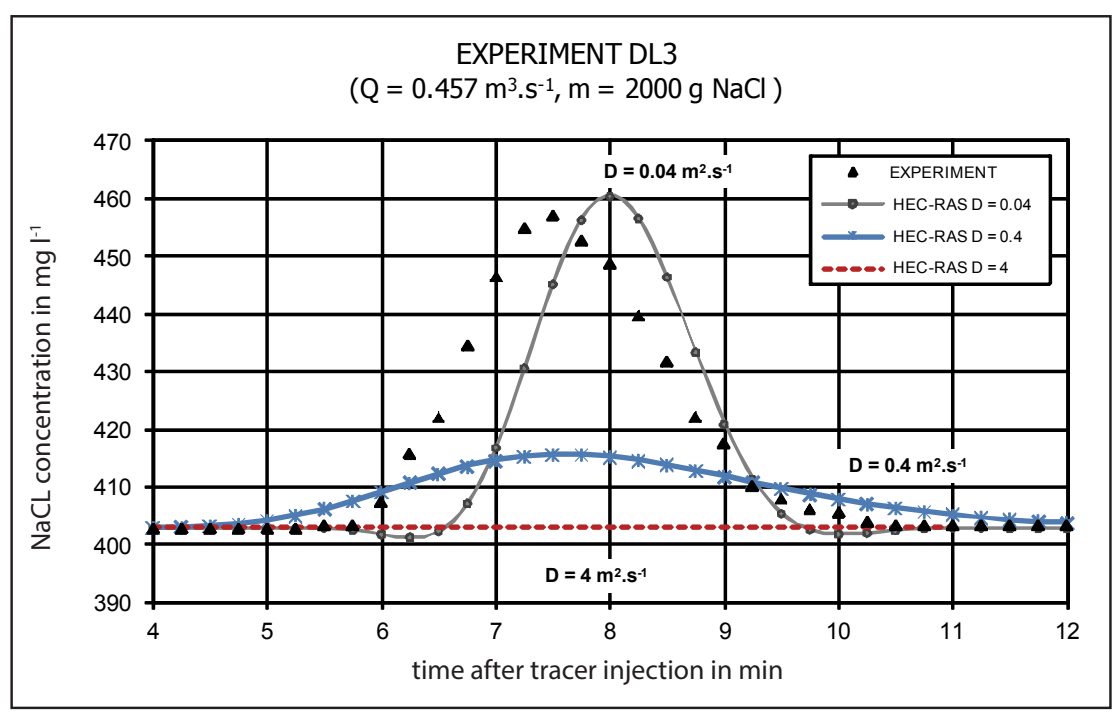

Figure 4a Concentration distribution bythe HEC-RAS model - discharge 0.457 $\mathrm{m}^{3} \mathrm{~s}^{-1}$; injection amount $2 \mathrm{~kg} \mathrm{NaCl}$; distance from injection point $100 \mathrm{~m}$

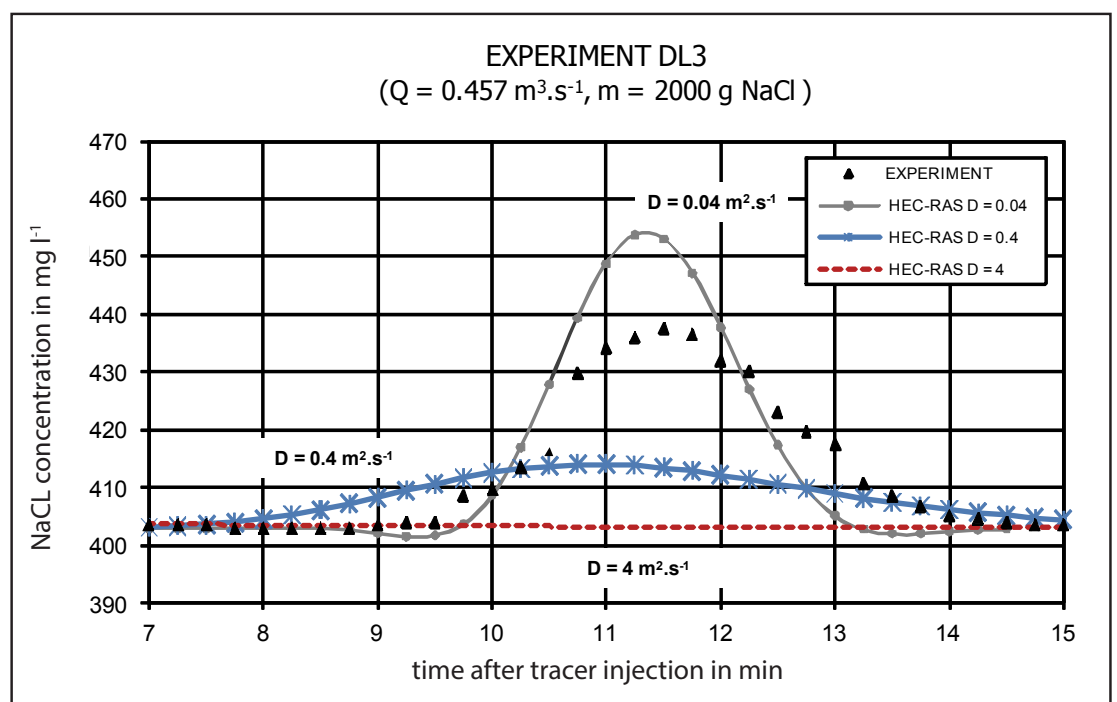

Figure 4b Concentration distribution by the HEC-RAS model - discharge $0.457 \mathrm{~m}^{3} \mathrm{~s}^{-1}$; injection amount $2 \mathrm{~kg} \mathrm{NaCl}$; distance from injection point $150 \mathrm{~mm}$

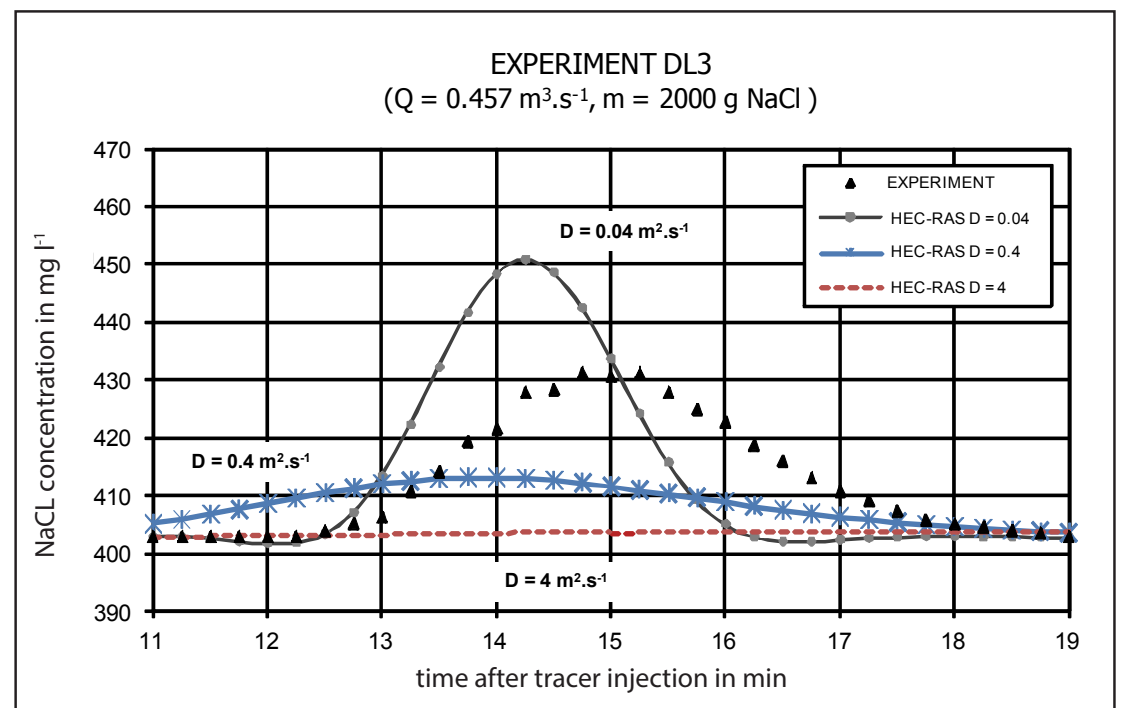

Figure 4c Concentration distribution by the HEC-RAS model - discharge 0.457 $\mathrm{m}^{3} \mathrm{~s}^{-1}$; injection amount $2 \mathrm{~kg} \mathrm{NaCl}$; distance from injection point $200 \mathrm{~m}$
1979; Říha, 2000). Next, the values of this coefficient obtained by the model seem to be variable along the investigated part of the stream. It can be the consequence that the model simulates the flow conditions in details and partially takes into consideration also transverse spreading through velocity distribution. The results from the HEC-RAS could also indicate that so-called mixing length (length along which the tracer spreads across the whole width of a stream) was not estimated right. In Figure 3 there is the next result of modelled situation in the Malá Nitra stream. It can be seen as an asymmetrical shape of the observed solute concentration curve, characterized by steep leading edges and prolonged tails (especially at $1,340 \mathrm{~m}$ from injection point). It is probably caused by transient storage occurrence when portions of transported solute become temporarily isolated from the main stream in a channel (De Smedt, et al., 2005). In our case it is due to existence of aquatic vegetation and dead zones in places of the bank failure in the downstream reach of the river. On base of the obtained results we may state that transient storage is important factor that is not included in water quality module of the HECRAS software that in cases of some specific conditions (relatively narrow river channel with dense aquatic vegetation) may affect model outputs.

The next goal was to evaluate the impact of longitudinal dispersion coefficients as input data on computed outputs of 1-D simulation model HEC-RAS. We simulated the pollution spread in the Malá Nitra stream during the same flow conditions (discharge and velocity distribution), with the same tracer/mass injection volume, only values of longitudinal dispersion coefficient were different. For this numerical experiment we chose three different values: $0.04 \mathrm{~m}^{2} \mathrm{~s}^{-1} ; 0.4 \mathrm{~m}^{2} \mathrm{~s}^{-1}$ and $4 \mathrm{~m}^{2} \mathrm{~s}^{-1}$.

Outputs from the model were compared with the measured values from the experiment with similar conditions. As it can be seen in Figure 4 , the model HEC-RAS responds to $D_{x}$ value changes adequately, suitably and proportionately. Besides, the results of this kind of numerical experiments show that the lower value 
of $D_{x}\left(0.04 \mathrm{~m}^{2} \mathrm{~s}^{-1}\right)$ is more acceptable at the beginning part of monitored length of the stream, with increasing distance from injection point the value of longitudinal dispersion coefficient increases. However, the value $4 \mathrm{~m}^{2} \mathrm{~s}^{-1}$ looks quite a high one and for this stream and flow conditions it is unreal and unsuitable.

The application of the model HEC-RAS demonstrated eligibility for simulation of pollution spreading in streams, which means that it is a suitable tool allowing a reasonable support in decision making process connected to river water quality management. Although the model is able to predict the parameters for practical applications, its use without previous calibration has limited reliability. This task is very urgent in rivers with many natural factors that may influence the longitudinal dispersion e.g. in-stream vegetation, geometric irregularities or existence of any kind of dead zones.

\section{Acknowledgements}

This paper was prepared with the support of the project no. APVV-0274-10, VEGA 1/0123/11, VEGA 1/0744/13, KEGA 003SPU-4/2012 and it is also the result of the project implementation ITMS 26240120004 Centre of excellence for integrated flood protection of land supported by the Research \& Development Operational Programme funded by the ERDF.

\section{References}

ABBOTT, M. B. 1978. Commercial and scientific aspects of mathematical modelling. Applied numerical modelling. In Proc $2^{\text {nd }}$ international conference, Madrid, September 1978, pp. 659-666.

DAVID, T. H. - PETER, S. - THEODORE, C. 2002. Determination of longitudinal dispersion coefficient and net advection in the Tidal Hudson River with a large-scale, high resolution SF6 tracer release experiment. In Environ. Sci. Technol., 2002, no. 36, pp. 3234-3241.

DE SMEDT, F. - BREVIS, W. - DEBELS, P. 2005. Analytical solution for solute transport resulting from instantaneous injection in streams with transient storage. In J. Hydrol., 2005, no. 315, pp. 25-39.

FISCHER, H. B. - LIST, E. - KOH, R. C. Y. - IMBERGER, J. - BROOKS, N. H. 1979. Mixing in Inland and Coastal Waters. Orlando : Academic Press, 1979.

FRENCH, R H. 1986. Open-Channel Hydraulics. New York : McGrawHill Book Company, 1986.
IGAZ, D. - ČIMO, J. - HORÁK, J. Evaluation of drought conditions in the Danube Plain. In Acta hydrologica slovaca, vol. 11, 2010, no. 2, pp. 375-381. ISSN 1335-6291.

JOLÁNKAI, G. 1992. Hydrological, chemical and biological processes of contaminant transformation and transport in river and lake systems. In A state of the art report, UNESCO, Paris, 1992. 147 p. JURÍK, L. - NOVOTNÁ, B. 2005. Hydrologic characteristics of the agricultural exploited landscape. In Acta horticulturae et regiotecturae. vol. 8, 2005, no. 1, pp. 18-20. ISSN 1335-2563.

MACURA, V. - ŠKRINÁR, A. - KALÚZ, K. - JALČOVÍKOVÁ, M. ŠKROVINOVÁ, M. 2012. Influence of the morphological and hydraulic characteristics of mountain streams on fish habitat suitability curves. In River Research and Applications, vol. 28, 2012, no. 8, pp. 1161-1178.

MCINSTYRE, N. - JACKSON, B. - WADE, A. J. - BUTTERFIELD, D. WHEATER, H. S. 2005. Sensitivity analysis of a catchment-scale nitrogen model. In Journal of Hydrology, vol. 315, 2005, no. 1-4, pp. 71-92.

PEKÁROVÁ, P. - VELÍSKOVÁ, Y. 1998. Water quality modelling in Ondava catchment. Bratislava : VEDA, 1998. ISBN 80-224-0535-3.

RANKINEN, K. - LEPISTO, A. - GRANLUND, K. 2002. Hydrological application of the INCA model with varying spatial resolution and nitrogen dynamics in a northern river basin, In Hydrology and Earth System Sciences, vol. 6, 2002, no. 3, pp. 339-350.

RUTHERFORD, J. C. River Mixing. New York : John Wiley \& Sons, 1994. ŘÍHA, J. - DOLEŽAL, P. - JANDORA, J. - OŠLEJŠKOVÁ, J. - RYL, T. 2000. Surface water quality and its mathematical modelling, Brno : NOEL, 2000. p. 269.

van GENUCHTEN, M. Th. - LEIJ, F. J. - SKAGGS, T. H. - TORIDE, N. - BRADFORD, S. A. - PONTEDEIRO, E. M. 2013. Exact analytical solutions for contaminant transport in rivers 1 . The equilibrium advection-dispersion equation. In J. Hydrol. Hydromech., vol. 61, 2013, no. 2, pp. 146-160.

USACE. HEC-RAS - River Analysis System Hydraulic Reference Manual Version 4.1, USACE 2010, 411 pp.

\section{Contact address}

Ing. Yvetta Velísková, PhD., Institute of Hydrology, Slovak Academy of Sciences, Račianska 75, 83102 Bratislava, Slovakia, phone 00421244456 937, e-mail: veliskova@ uh.savba.sk 